\title{
Heavy load carrying and adverse reproductive health among women in Tanzania and Nepal: a comparative study
}

\author{
Aybüke Koyuncu 1, ${ }^{,}$, Jillian L. Kadota ${ }^{2}$, Agatha Mnyippembe ${ }^{3}$, Prosper F. Njau ${ }^{4}$, Tula Ram Sijali \\ 5, Sandra I. McCoy ${ }^{6}$, Michael N. Bates ${ }^{7}$, Carisa Harris-Adamson ${ }^{8}$, Ndola Prata ${ }^{9}$ \\ 1 Division of Epidemiology \& Biostatistics, University of California, Berkeley, USA; $\underline{\text { akoyuncu@berkeley.edu }}$ \\ 2 Division of Epidemiology \& Biostatistics, University of California, Berkeley, USA; jill.kadota@berkeley.edu \\ 3 Health for a Prosperous Nation, Dar es Salaam, Tanzania; amnyippembe@gmail.com \\ 4 Prevention of Mother-to-Child HIV Transmission Programme, Ministry of Health, Community \\ Development, Gender, Elderly, and Children, Dar es Salaam, Tanzania; prosperpendo@gmail.com \\ 5 Institute of Social and Environment Research-Nepal (ISER-N), Kaski, Nepal; sijali.tula@gmail.com \\ 6 Division of Environmental Health Sciences and Division of Epidemiology \& Biostatistics, University of \\ California, Berkeley, USA; smccoy@berkeley.edu \\ 7 Division of Epidemiology \& Biostatistics, University of California, Berkeley, USA; m_bates@berkeley.edu \\ 8 Division of Environmental Health Sciences, University of California, Berkeley and Department of \\ Medicine, University of California, San Francisco, USA; carisaharris@berkeley.edu \\ 9 Bixby Center for Population, Health and Sustainability, School of Public Health, University of California, \\ Berkeley, USA; ndola@berkeley.edu \\ * Correspondence: akoyuncu@berkeley.edu
}

\begin{abstract}
Heavy load carrying of water, firewood, and sand/stones is a ubiquitous activity for women living in developing countries. Although the intra-abdominal pressure associated with heavy load carrying is hypothesized to increase the risk of pelvic organ prolapse (POP) among women, relevant epidemiologic data are lacking. We conducted a comparative study involving two exploratory cross-sectional studies among convenience samples of women carrying heavy loads, with different characteristics: (1) as part of their activities for daily living, in Shinyanga region, Tanzania; and (2) working as sand miners in Pokhara, Nepal. Women were categorized has having "low" or "high" load-carrying exposures based on the measured weights of the loads being carried at the time of the survey, as well as on self-reported duration and frequency of load carrying. A summary score for reproductive health discomfort suggestive of POP was generated using questions from the Pelvic Organ Prolapse Distress Inventory (POPDI-6). Women with higher load carrying exposures had on average higher reproductive health discomfort scores in both Tanzania (adjusted prevalence difference $\left(\mathrm{PD}_{\mathrm{a}}\right)=3.7 ; 95 \% \mathrm{CI}$ : -3.8-11.3; $\mathrm{p}=0.33$ ) and Nepal ( $\mathrm{PD}_{\mathrm{a}}=9.3 ; 95 \% \mathrm{CI}$ : 4.9-23.6; $\mathrm{p}=0.18$ ). We identified trends suggestive of an association between increasing heavy load carrying exposures and symptoms of reproductive health discomfort. Our findings underscore the need for larger epidemiologic studies of the potential adverse reproductive health effects of heavy load carrying activities on women in developing countries.
\end{abstract}

Keywords: pelvic organ prolapse (POP); uterine prolapse; heavy load carrying

\section{Introduction}

Pelvic organ prolapse (POP) is a common reproductive health condition estimated to affect approximately $19 \%$ of women in low- and middle-income countries (LMIC) [1]. POP is caused by the weakening of muscles and tissues supporting the pelvis, ultimately resulting in one or more of the 
pelvic organs (e.g. uterus, bladder, rectum) dropping from their normal position [2]. Women living with POP experience chronic symptoms, such as incontinence and severe pain, when walking, urinating, defecating, completing daily tasks, and during sexual activity [3]. While, globally, POP typically occurs in women of post-menopausal age, the highest prevalence of POP in LMIC is found in women of reproductive age [4]. The stigma and shame associated with POP, combined with patriarchal societal structures in many LMIC, likely contributes to an underestimation of the prevalence of POP [4-6]. In developing countries. such as Tanzania and Nepal, the pain and discomfort of $\mathrm{POP}$ are compounded by negative emotional effects from societal discrimination, as well as spousal and intrafamilial abuse due to women's impaired abilities to complete household chores (e.g., collecting water, cooking) [4-7]. POP also increases women's vulnerability to genderbased domestic violence if they refuse sex with their spouses, because of pain during intercourse [46]. Nonetheless, there has been little research on the extent of the problem, risk factors, or interventions.

In addition to known risk factors for POP, such as early childbearing, inadequate pregnancy spacing, and prolonged or difficult labor, heavy-load carrying has been implicated as a potential contributor to high rates of POP in developing countries [1,8-11]. Heavy lifting increases abdominal pressure and strain on the muscles and ligaments supporting pelvic organs [12,13]. Women in developed countries with occupations involving heavy lifting have been shown to have increased odds of genital prolapse compared to the general population [10] and other occupations with less frequent load carrying [11]. In LMICs, the extent to which individuals carry heavy loads for long distances is determined by their access to water, fuel, and transportation, which is highly influenced by source of income and socio-economic status. Domestic load carrying in areas of Sub-Saharan Africa and Asia without piped water or electricity is predominantly performed by female household members, starting as early as 10 years of age $[14,15]$. In sub-Saharan Africa, loads are carried using buckets or baskets balanced atop of the head; typical loads are between 25-35 kilograms (kg), but up to $60 \mathrm{~kg}$ has been reported [14]. Load carrying also provides a source of income in countries such as Nepal, where, for example, the excavation and transport of sand and stones from riverbeds provides a means of livelihood for many poor families [16].

Although the magnitude, frequency and duration of the loads carried regularly by women in developing countries suggest such practices may contribute to adverse reproductive health outcomes, including POP, epidemiologic data are limited. In clinic-based descriptive studies heavy load carrying has been documented as a prevalent practice among women with POP [7,17], however few studies have examined heavy load carrying as a predictor of POP. According to mainly anthropologic research, women experiencing POP in developing countries frequently report heavy load carrying and strenuous physical labor during the postpartum period as perceived causes of POP $[5,7,18]$. In the few relevant studies conducted to date, load carrying has been identified as a risk factor for POP in some settings [19,20], but not in others [21]. A sample of women in Tanzania carrying heavy objects for $\geq 2$ hours per day had almost 5 times the odds of POP compared to those who did not carry heavy objects (95\% CI: 1.7-13.2) [20], while carrying heavy objects for at least 12 hours a week was not a risk factor for POP among a sample of women in Nepal [21]. This may reflect varied characteristics of load carrying by women including the weight of the load, the load carrying duration (determined by distances travelled), and the frequencies of load carrying. The type of load (wood, bricks, water) and the mode of carriage (atop head versus on back) could also 
contribute to the overall biomechanical strain on the musculoskeletal tissues that support the pelvic organs. Variations in mode of carriage may lead to different health-related outcomes.

To increase understanding of the complex relationship between characteristics of lifting and POP, we conducted two exploratory cross-sectional studies in separate populations of women with very different heavy load carrying practices in Tanzania and Nepal.

\section{Materials and Methods}

Study populations were selected because of their different load carrying characteristics (mode of carriage, load weights, frequency and duration of carriage). The study population in Shinyanga Region, Tanzania included women carrying loads as part of their activities for daily living. Of Tanzania's 26 regions, Shinyanga is characterized by high poverty levels [22]. Considered a lowstatus activity in this setting, 'domestic load-carrying' is frequently undertaken by women starting at a very young age [14]. Women walk long distances to collect and carry home a variety of household necessities, such as water, firewood, agricultural products (grains, corn, ground corn, etc.), coal, sand or rocks [23].

In Nepal, the study population was comprised of sand miners working in Kaski district. Details about the population at the sand mining site from which our participants were recruited has been previously described [24]. Briefly, sand miners in Nepal work seasonally to excavate sand and stones that have accumulated in river beds during the monsoon season (generally, May to September). Both men and women participate and typically operate in small groups to manually excavate and transport sand and rocks from river beds up river banks to collection trucks. Women engage in a variety of tasks, including sorting and sifting sand and stones using sieves, carrying loads short distances within excavation areas, and transporting loads up river-banks to collection trucks. Miners are typically paid according to the number of truck-loads they fill.

The two study populations are distinguished particularly by modes of load carriage, the sizes of their loads, and distances and frequencies of load carriage. Women from the study population in Tanzania carried loads balanced atop their heads (Figure 1), while women in Nepal carried loads using a cone-shaped basket called a "doko", supported on their back with a circular band called a "namlo," looped around the forehead (Figure 2). The Tanzanian population carried lighter and fewer loads, but for longer distances, while the Nepali population carried very heavy loads relatively short distances and more frequently. 


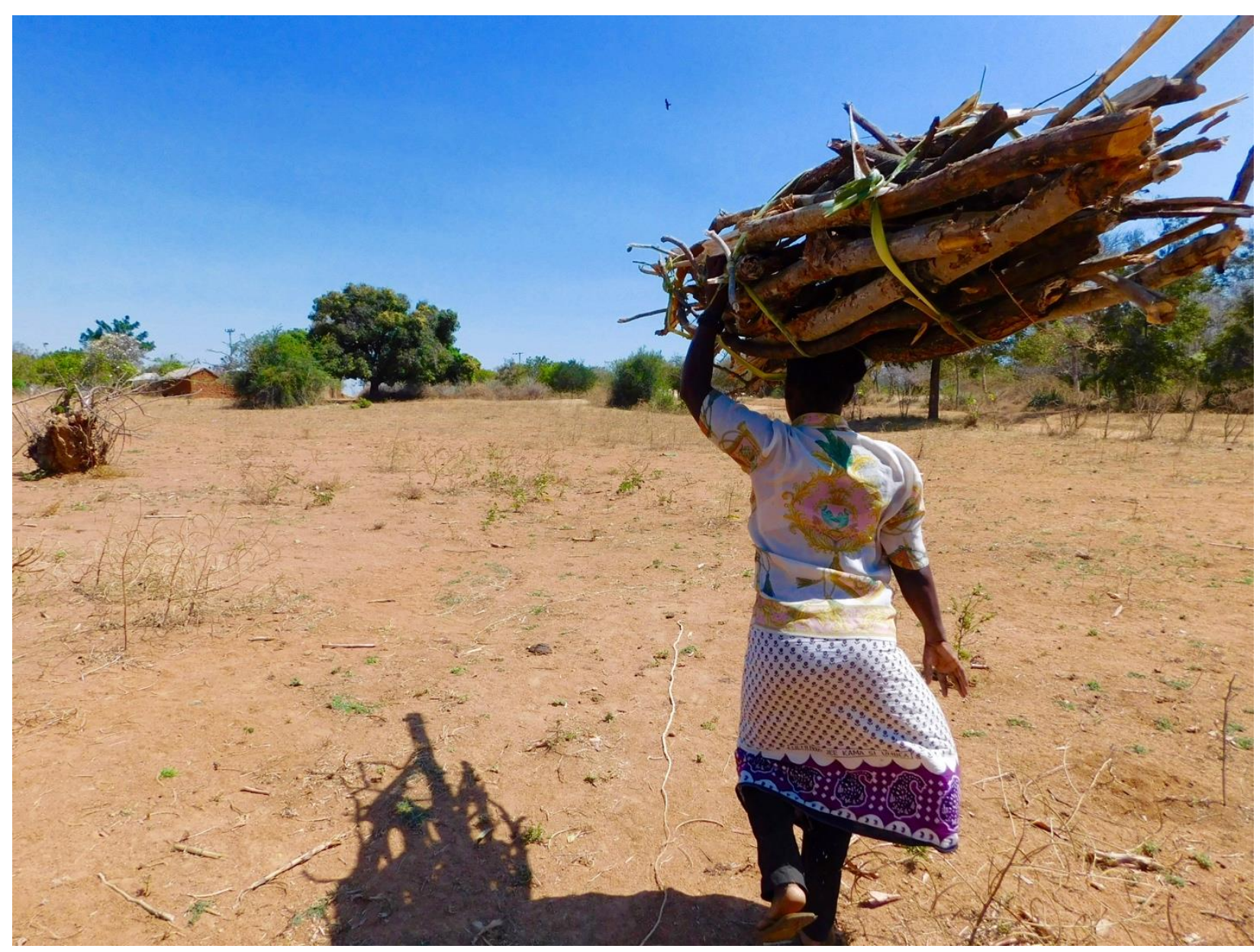

Figure 1. A female carrying a load of wood in Shinyanga region, Tanzania, July-August 2016 


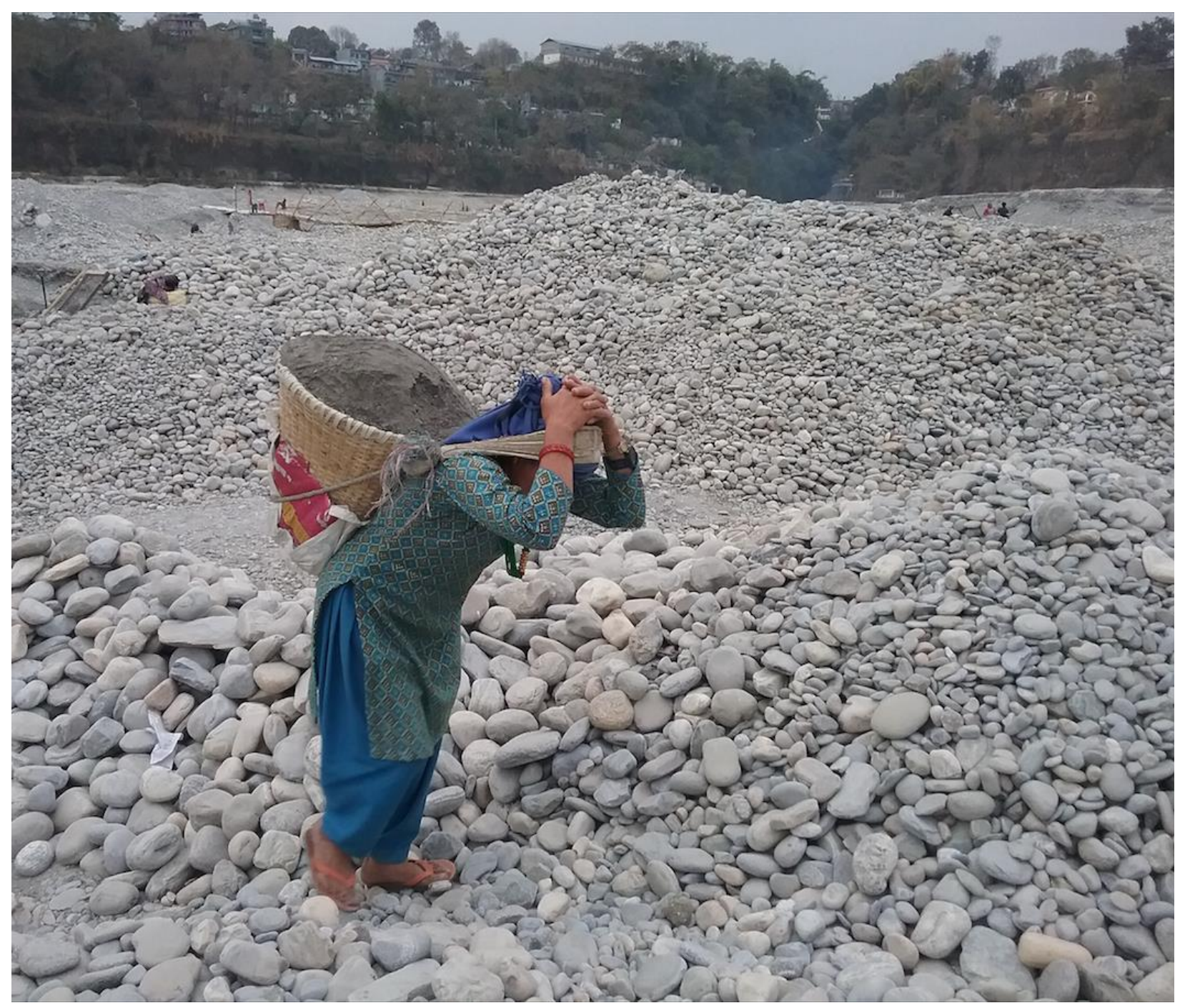

Figure 2. A female sand-miner carrying a load of sand using a doko and namlo at a sand mining site at the Seti River in Pokhara, Kaski district, Nepal, December-January 2017

In both study settings, eligible participants were a convenience sample of women, 18 years or older, passing a study recruitment site carrying a load. In Tanzania, study recruitment sites were established at locations near water collection points and along farm and market routes [23]. In Nepal, a sand mining site along the Seti River in Pokhara city served as the primary recruitment site [24].

Data collection took place from July-August 2016 and December-January 2017 in Tanzania and Nepal, respectively. Women who provided written informed consent by signature or thumbprint completed an interviewer-administered survey which collected information on socio-demographics, load-carrying practices, and reproductive health. The height and weight of each participant, as well as the weight of the load being carried at time of study recruitment, were measured upon survey completion. Interviewer observations covered the type of load being carried at the time of study recruitment and the method of load carrying (e.g. atop head, on back, etc.).

Participants were asked to report their average load-carrying duration (number of minutes per load carried) and frequency of carrying (number of loads carried per week). Data on duration, frequency, and the weight of the load carried at the time of study recruitment were used to generate a summary index of load-carrying practices using principal component analysis (PCA) [25]. Data patterns within the various simultaneously occurring dimensions of load carrying were captured 
using the first component of the PCA [25]. For participants in Tanzania, the summary index for load carrying incorporated the self-reported duration and frequency for all loads carried as part of daily activities (e.g. carrying loads of wood, water or other household necessities). In contrast, the summary index for the Nepali participants was constructed using self-reported duration and frequency of occupational loads of sand or stones. Separately, for both datasets, the summary index of loadcarrying exposures was dichotomized using the median index score to indicate "low" or "high" loadcarrying exposure index.

Additional data on load-carrying activities were collected from a sub-sample of study participants in Tanzania to corroborate self-reported load-carrying practices. Specifically, a wristwatch-like device enabled with GPS capabilities was utilized to assess distance traveled by women over a 24-hour wearing period. In order to capture the number of loads carried during each 24-hour period, participants were asked to press a button on the wristwatch-like device each time a new load was carried during the wearing period.

Symptoms of reproductive health discomfort were measured using questions from the Pelvic Organ Prolapse Distress Inventory (POPDI-6) validated scale (see Supplementary Materials) [26]. The POPDI-6 scale is a subset of questions within the psychometrically validated Pelvic Floor Distress Inventory (PFDI-20), a condition-specific questionnaire used to measure the extent to which POP symptoms affect an individual's quality of life among women with symptomatic POP [26-28]. Questions from the validated short-form version of the POPDI-6 scale, used as a screening tool in each study population, included questions on the presence of: 1) pressure in the lower abdomen, 2) heaviness/dullness in the pelvic area, and 3) the presence of a bulge in the vaginal area. Participants indicated the presence or absence of each symptom. The participant also rated the degree to which each symptom bothered her, with " 0 " indicating symptom not present; " 1 ", symptom present but not bothersome; "2", symptom present and somewhat bothersome; "3", symptom present and moderately bothersome; and " 4 ", symptom present and quite bothersome. Symptom ratings were used to generate a continuous summary score of possible POP-related reproductive health discomfort. Separately, in each study population, this summary score was dichotomized at the median into "low" and "high" scores. In addition to symptoms of POP captured in the POPDI-6 scale, participants were asked about any problems they had in holding urine and about pain during urination. Although urinary incontinence/pain during urination are frequent symptoms of POP [2], they were not included in the summary score of reproductive health discomfort due to their low sensitivity for POP and possible association with other unrelated health conditions, such as urinary tract infections.

To gain a better understanding of the symptoms contributing most significantly to POPrelated reproductive health discomfort in each study population, we examined the association between individual symptoms of reproductive health discomfort and the overall POPDI score using linear regression models. All models were adjusted for potential confounders specified a priori as epidemiologically relevant and included continuous variables for body mass index (BMI), age, and parity.

The relationship between load-carrying exposures and reproductive health discomfort suggestive of POP was modeled separately in each study population. Linear probability models were used to examine the unadjusted and adjusted associations between the summary indexes of load carrying exposures and summary scores of reproductive health discomfort suggestive of POP. Fully adjusted models included all covariates specified a priori (i.e., BMI, age, and parity). Using adjusted 
logistic regression, we examined the predicted probability of high/low reproductive health discomfort by load-carrying exposures.

Statistical significance of parameter estimates was evaluated at the two-sided alpha level of $\mathrm{p}<0.05$. All analyses were conducted using STATA 14 (College Station, Texas).

This study was approved by the IRB at the University of California, Berkeley (Protocol number 2016-02-8461 and 2017-07-10156) and the ethical review boards at the National Institute of Medical Research (NIMR) of Tanzania and the Nepal Health Research Council. No subject participated before providing informed consent.

\section{Results}

The combined study population was 102 women, including 80 in Tanzania (mean age 31.6 (SD: 12.2)) and 22 in Nepal (mean age 36.1 (SD: 8.1)). Women reported having given birth an average of 4.0 (SD: 2.5) and 3.4 (SD: 2.2) times, in Tanzania and Nepal, respectively (Table 1). Most participants had normal or overweight body mass index (BMI), and the proportion of participants who were overweight was higher in Nepal than in Tanzania (46\% vs 34\%).

Table 1. Characteristics of the study samples of women, Shinyanga Region, Tanzania and Kaski District, Nepal, 2016-2017

\begin{tabular}{|c|c|c|c|c|}
\hline \multirow[b]{2}{*}{ Participant Characteristic } & \multicolumn{2}{|c|}{$\begin{array}{c}\text { Tanzania } \\
(\mathrm{N}=\mathbf{8 0})\end{array}$} & \multicolumn{2}{|c|}{$\begin{array}{l}\text { Nepal } \\
(\mathrm{N}=22)\end{array}$} \\
\hline & Mean (SD) & $\mathbf{N}(\%)$ & Mean (SD) & $\mathbf{N}(\%)$ \\
\hline Age (years) & $31.6(12.2)$ & & $36.1(8.1)$ & \\
\hline $18-30$ & & $47(57.3)$ & & $8(36.4)$ \\
\hline$>30$ & & $26(31.7)$ & & $14(63.6)$ \\
\hline Unknown & & $9(11.0)$ & & $0(0.0)$ \\
\hline BMI $\left(\mathbf{k g} / \mathbf{m}^{2}\right)$ & $24.4(4.2)$ & & $24.7(3.7)$ & \\
\hline Underweight $(<18.5)$ & & $2(2.4)$ & & $1(4.6)$ \\
\hline Normal (18.5-25) & & $55(67.1)$ & & $11(50.0)$ \\
\hline Overweight $(>25)$ & & $27(32.9)$ & & $10(45.5)$ \\
\hline \multicolumn{5}{|l|}{ Marital status } \\
\hline Married/with partner & & $61(74.4)$ & & $17(77.3)$ \\
\hline Unmarried/Single/Divorced/Separated & & $21(25.6)$ & & $4(22.7)$ \\
\hline \multicolumn{5}{|l|}{ Caste/ethnicity ${ }^{\mathrm{A}}$} \\
\hline Dalit & - & - & & $5(22.7)$ \\
\hline Brahmin/chhetri & - & - & & $1(4.6)$ \\
\hline Janajati & - & - & & $16(72.7)$ \\
\hline \multicolumn{5}{|l|}{ Primary Occupation } \\
\hline Farmer & & $78(95.1)$ & & $0(0.0)$ \\
\hline Sand miner & & $0(0.0)$ & & $22(100.0)$ \\
\hline Other & & $4(4.9)$ & & $0(0.0)$ \\
\hline Years working as a sand miner & - & - & & $8.4(9.3)$ \\
\hline Parity & $4.0(2.5)$ & & $3.4(2.2)$ & \\
\hline
\end{tabular}


0-3 children

Number of lifetime pregnancies

None
$1-2$ pregnancies
$3-4$ pregnancies
$\geq 5$ pregnancies

Age at first child (years)
$45(54.9)$

$37(45.1)$

$4.4(3.1)$

$3(3.7)$

13 (15.9)

$33(40.2)$

$33(40.2)$

$18.1(2.2)$
$13(59.1)$

$9(40.9)$

$3.9(2.5)$

$6(27.3)$

$5(22.7)$

$9(40.9)$

$19.7(4.5)$

$10(45.5)$

$10(45.5)$

$2(9.1)$

BMI = body mass index

A Castes originate from the Hindu religion and are hierarchical groups based on social stratification. In Nepali culture, the

Dalit represent a low caste group, Brahmin/Chhetri are high caste Hindus, and Janjati are indigenous populations

\subsection{Load-carrying exposures}

Load-carrying exposures for our participants in Tanzania have been previously reported [23]. Briefly, on the interview-date, women were carrying loads of water $(n=51 ; 62 \%)$, wood $(n=17 ; 21 \%)$ or agricultural products $(\mathrm{n}=14 ; 17 \%)$. The average weight of all loads measured in Tanzania was $20.0 \mathrm{~kg}$ (SE: 0.6): water weighed an average of $20.4 \mathrm{~kg}$ (SE: 0.6), wood $21.0 \mathrm{~kg}$ (SE: 2.3), and agricultural products $15.9 \mathrm{~kg}$ (SE: 1.2). Women reported carrying an average of 3 loads per day in the last 7 days (SE: 0.2), corroborated by information collected using GPS devices from a sub-sample of study participants ( $n=14)$. GPS data revealed an average of 3.6 load-carrying trips per day (range: 1-9 trips), covering an average total distance of 5.32 miles over the course of the 24-hour wearing period [23]. Those categorized in the "high" load-carrying exposure index group carried a slightly heavier average load weight, but at a greater frequency compared to those in the "low" index group (weight: $20.0 \mathrm{~kg}$ (SE: 0.9) versus $19.2 \mathrm{~kg}$ (SE: 0.9); frequency: 33.5 loads/week (SE: 2.3) versus 11 loads/week (SE: 0.9), respectively).

Women in Nepal were carrying loads exclusively of sand and stones. Compared to women in Tanzania, women in Nepal carried substantially heavier loads for shorter durations and higher frequencies per week (Table 2). The median loads carried by female sand miners were $65.5 \mathrm{~kg}$ (SE: 2.2), and women reported carrying loads a median of 165.5 times per week (SE: 115.9) for less than 1 minute per load (SE: 0). Sand-miners in the "high" heavy load carrying exposure category were characterized by having reported, on average, carrying lighter loads for longer durations/frequencies when compared to those in the "low" exposure category(weight: $69.8 \mathrm{~kg}$ (SE: 1.6) versus $57.5 \mathrm{~kg}$ (SE: 1.7); frequency: 140.0 loads/week (SE: 343.3) versus 210.0 loads/week (SE: 155.7), respectively).

Table 2. Summary of load carrying exposures, Shinyanga Region, Tanzania and Kaski Region, Nepal, 2016-2017

\section{Characteristic}

Median

(IQR)

\section{Tanzania}

Nepal

\begin{tabular}{|c|c|c|c|c|c|}
\hline $\begin{array}{l}\text { Overall } \\
(\mathrm{N}=80)\end{array}$ & $\begin{array}{c}\text { Low load } \\
\text { carrying } \\
(n=40)\end{array}$ & $\begin{array}{l}\text { High load } \\
\text { carrying } \\
(n=40)\end{array}$ & $\begin{array}{l}\text { Overall } \\
(\mathrm{N}=22)\end{array}$ & $\begin{array}{l}\text { Low load } \\
\text { carrying } \\
(n=11)\end{array}$ & $\begin{array}{c}\text { High load } \\
\text { carrying } \\
(n=11)\end{array}$ \\
\hline
\end{tabular}




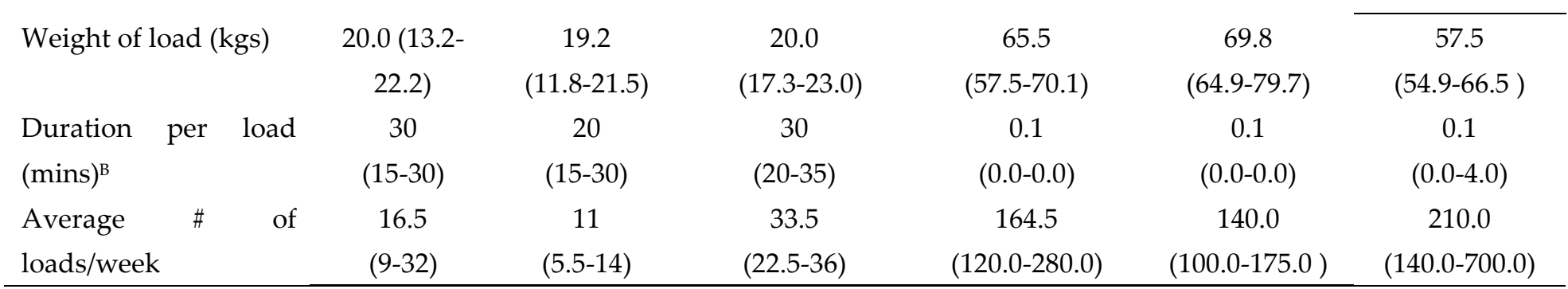

IQR: Interquartile range

A Summary index of load carrying generated using polychoric principle component analysis of load carrying duration, frequency, and weight. Dichotomized using the median index score to indicate "low" or "high" load carrying exposure.

BSelf-reported load carrying duration 0.1 minutes per load was representative of durations $<1$ minute

\subsection{Symptoms of POP-related Reproductive Health Discomfort and POPDI-6 score}

Among the Tanzanian women, almost half reported feelings of heaviness or dullness in the pelvic area, as well as pressure in the lower abdomen $(\mathrm{n}=38 ; 47.5 \%)$ and $21(26.3 \%)$ had symptoms consistent with incontinence (Table III). Twelve women (15.0\%) reported that they had a bulge that they could either see or feel in their vaginal area. This was associated with the largest mean increase in the summary score for POP-related reproductive discomfort (adjusted prevalence difference $\left.\left(\mathrm{PD}_{\mathrm{a}}\right)=11.7 ; 95 \% \mathrm{CI}: 8.4,15.0\right)$.

Table 3. Association between symptoms of POP-related reproductive discomfort and summary discomfort score, Tanzania and Nepal, 2016-2017

\begin{tabular}{|c|c|c|c|c|c|c|c|}
\hline \multirow[t]{2}{*}{$\begin{array}{l}\text { Symptoms of } \\
\text { reproductive } \\
\text { discomfort }\end{array}$} & health & & Tanzania $(\mathrm{N}=$ & & & Nepal $(\mathrm{N}=$ & \\
\hline & & $\begin{array}{c}\mathrm{N} \\
\text { (col \%) }\end{array}$ & $\begin{array}{c}\text { Unadjusted } \\
\text { PD } \\
(95 \% \mathrm{CI})\end{array}$ & $\begin{array}{c}\text { Adjusted } \\
\text { PD } \\
(95 \% \mathrm{CI})\end{array}$ & $\begin{array}{c}\mathrm{N} \\
\text { (col \%) }\end{array}$ & $\begin{array}{c}\text { Unadjusted } \\
\text { PD } \\
(95 \% \mathrm{CI})\end{array}$ & $\begin{array}{c}\text { Adjusted }{ }^{1} \\
\text { PD } \\
(95 \% \mathrm{CI})\end{array}$ \\
\hline \multicolumn{8}{|l|}{ Pain urinating } \\
\hline & No & $\begin{array}{c}32 \\
(39.0)\end{array}$ & 0.00 (ref) & 0.00 (ref) & $\begin{array}{c}14 \\
(63.6)\end{array}$ & 0.00 (ref) & 0.00 (ref) \\
\hline & Yes & $\begin{array}{c}50 \\
(61.0)\end{array}$ & $\begin{array}{c}11.9^{* *} \\
(4.7,19.1)\end{array}$ & $\begin{array}{c}11.2^{* *} \\
(4.1,18.4)\end{array}$ & $\begin{array}{c}8 \\
(36.4)\end{array}$ & $\begin{array}{c}14.9^{*} \\
(3.7,26.1)\end{array}$ & $\begin{array}{c}15.1^{*} \\
(3.6,26.7)\end{array}$ \\
\hline \multirow[t]{3}{*}{$\begin{array}{l}\text { Problems } \\
\text { urine }\end{array}$} & holding & & & & & & \\
\hline & No & $\begin{array}{c}59 \\
(73.8)\end{array}$ & 0.00 (ref) & 0.00 (ref) & $\begin{array}{c}18 \\
(81.8)\end{array}$ & 0.00 (ref) & 0.00 (ref) \\
\hline & Yes & $\begin{array}{c}21 \\
(26.3)\end{array}$ & $\begin{array}{c}9.4^{* *} \\
(6.7,12.1)\end{array}$ & $\begin{array}{c}9.5^{* *} \\
(6.8,12.1)\end{array}$ & $\begin{array}{c}4 \\
(18.2)\end{array}$ & $\begin{array}{c}1.4 \\
(-15.4,17.8)\end{array}$ & $\begin{array}{c}3.4 \\
(-14.2,20.9)\end{array}$ \\
\hline
\end{tabular}

Pressure in lower abdomen

$\begin{array}{llllll}\text { No } \quad 42 & 0.00(\text { ref }) & 0.00(\text { ref }) & 20(90.9) & 0.00(\text { ref }) & 0.00 \text { (ref) }\end{array}$




$\begin{array}{ccccccc}\text { Yes } & 38 & 11.0^{* *} & 10.7^{* *} & 2 & 33.3^{* *} & 36.6^{* *} \\ & (47.5) & (8.4,13.6) & (8.1,13.4) & (9.1) & (17.7,49.0) & (22.3,51.0)\end{array}$

\section{Heaviness/dullness}

in pelvic area

$\begin{array}{ccccccc}\text { No } & 42 & 0.00(\mathrm{ref}) & 0.00(\mathrm{ref}) & 18 & 0.00(\mathrm{ref}) & 0.00 \text { (ref) } \\ & (52.5) & & & (81.8) & & \\ \text { Yes } & 38 & 11.7^{* *} & 11.6^{* *} & 4 & 31.9^{* *} & 31.8^{* *} \\ & (47.5) & (9.1,14.2) & (8.9,14.3) & (18.2) & (25.0,38.9) & (24.9,38.7)\end{array}$

\section{Bulge in vagina}

\begin{tabular}{ccccccc} 
No & 68 & $0.00($ ref $)$ & $0.00($ ref $)$ & 21 & 0.00 (ref) & 0.00 (ref) \\
& $(85.0)$ & & & $(95.5)$ & & 12.8 \\
Yes & 12 & $12.1^{* *}$ & $11.7^{* *}$ & 1 & 18.7 & 12.9 \\
& $(15.0)$ & $(8.8,15.4)$ & $(8.4,15.0)$ & $(4.6)$ & $(-10.5,47.8)$ & $(-23.9,49.5)$ \\
\hline
\end{tabular}

${ }^{1}$ Adjusted for BMI, age, parity

PD: Prevalence difference; CI: Confidence interval

P-value: * $\mathrm{p}<0.05,{ }^{* *} \mathrm{p}<0.01$

The most prevalent symptoms of reproductive health discomfort among women in Nepal were pain while urinating (36.4\%), problems holding urine (18.2\%), and heaviness/dullness in the pelvic area (18.2\%) (Table III). Among all symptoms, pressure in the lower abdomen ( $\mathrm{PD}_{\mathrm{a}}=36.6$; 95\% CI: 22.3, 51.0) and heaviness/dullness in the pelvic area ( $\left.\mathrm{PD}_{a}=31.895 \% \mathrm{CI}: 24.9,38.7\right)$ were associated with the largest mean increases in overall reproductive health discomfort scores.

\subsection{Load carrying and reproductive health discomfort}

In both study populations, compared to women with lower load carrying exposure index, those with higher such indexes had larger mean POP-related reproductive health discomfort scores, although confidence intervals included the null in unadjusted and adjusted analyses (Table IV). The magnitude of the association between load carrying and reproductive discomfort was higher among study participants in Nepal ( $\mathrm{PD}_{\mathrm{a}}=9.3$; 95\% CI: -4.9-23.6; $\mathrm{p}=0.18$ ) compared to Tanzania ( $\mathrm{PD}_{\mathrm{a}}=3.7 ; 95 \%$ CI: -3.8-11.3; $p=0.33$ ). Using the best-fitting line for our logistic regression model, with the summary index for load carrying modeled as a continuous variable, a woman with load carrying exposures corresponding to the average summary index score had $45 \%$ and $12.2 \%$ predicted probabilities of having high reproductive health discomfort, in Tanzania and Nepal, respectively (Figures $3 \& 4$ ).

Table 4. Association between heavy load carrying and summary reproductive health discomfort score, Tanzania and Nepal, 2016-2017

\begin{tabular}{ccccc}
\hline & Heavy & Mean & Unadjusted & Adjusted \\
Load & Discomfort & PD & PD ${ }^{1}$ \\
& Carrying & $\begin{array}{c}\text { Score } \\
(\text { SD) }\end{array}$ & $\mathbf{( 9 5 \% ~ C I ) ~}$ & $\mathbf{( 9 5 \% ~ C I ) ~}$ \\
& \multirow{2}{*}{ Low } & 16.4 & 0.00 & 0.00 \\
\multirow{2}{*}{ Tanzania } & $(14.8)$ & $($ Ref $)$ & (Ref) \\
\hline
\end{tabular}




\begin{tabular}{ccccc}
\hline & & & \\
& High & 19.8 & 3.4 & 3.7 \\
& & $(18.7)$ & $(-4.1,11.0)$ & $(-3.8,11.3)$ \\
Nepal & & & 0.00 & 0.00 \\
& & 4.5 & $($ Ref $)$ & $($ Ref $)$ \\
& High & $(8.4)$ & 8.50 & 9.3 \\
& & $(13.1$ & $(-3.5,20.5)$ & $(-4.9,23.6)$ \\
\hline
\end{tabular}

${ }^{1}$ Adjusted for BMI, age, parity

PD: Prevalence difference; CI: Confidence interval

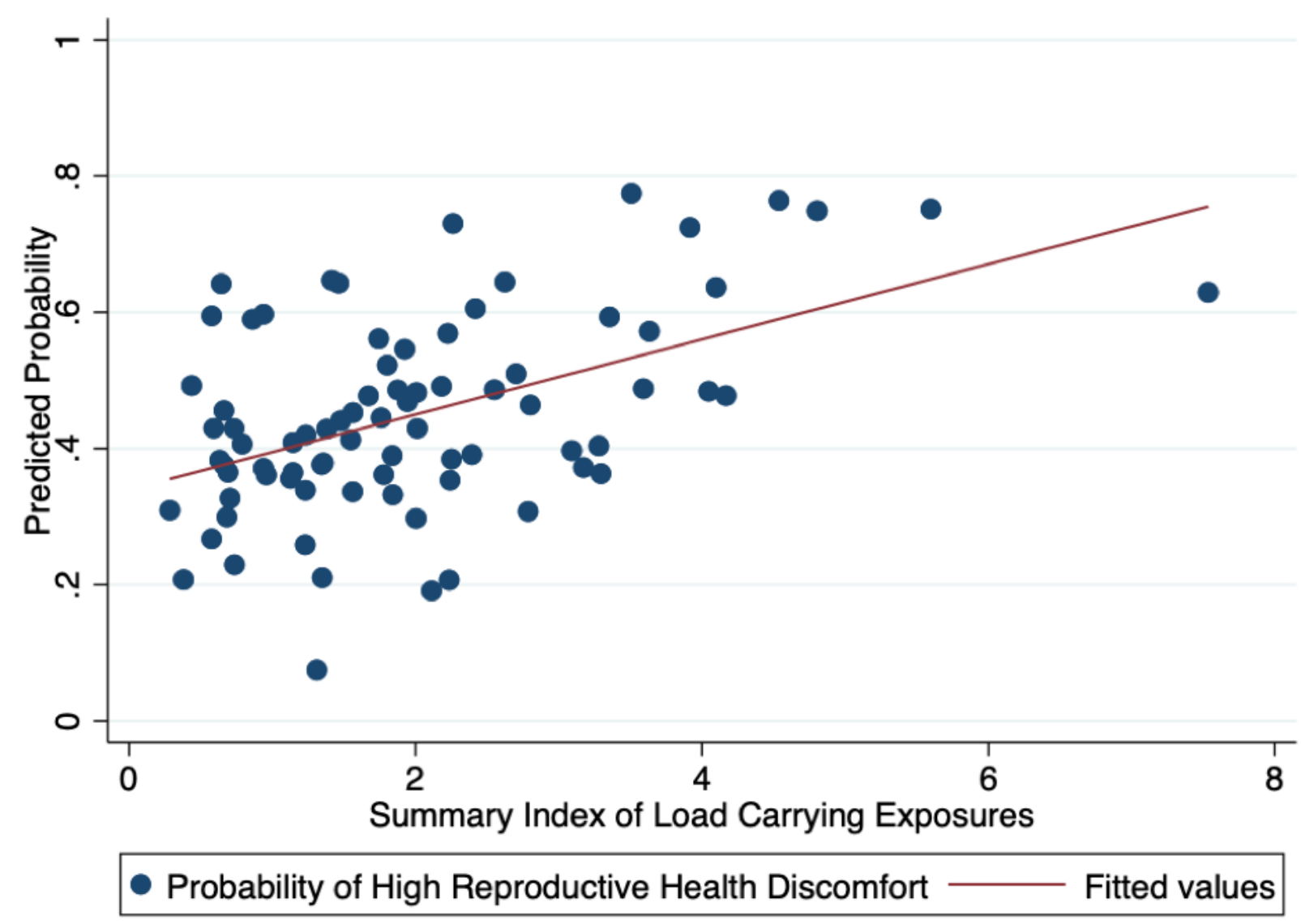

Figure 3. Predicted probability of high reproductive health discomfort with load carrying exposures (continuous), Tanzania, July-August 2016. 


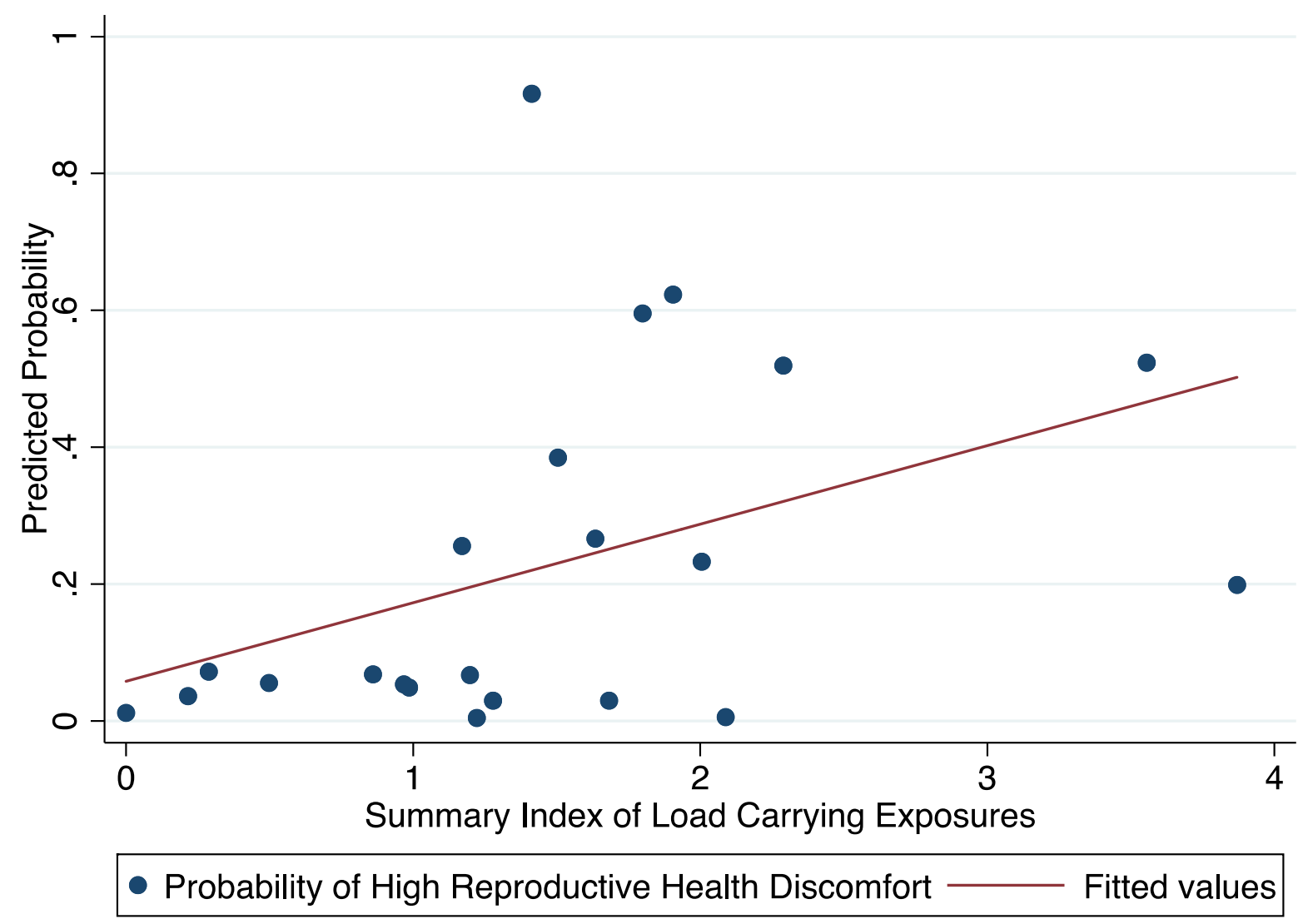

Figure 4. Predicted probability of high reproductive health discomfort with load carrying exposures (continuous), Nepal, December-January 2017.

\section{Discussion}

In two exploratory cross-sectional studies conducted among in Tanzania and Nepal, we quantified the burden of load carrying experienced by women as part of their daily household and income-generating activities and identified a substantial burden of reproductive health discomfort, with trends suggestive of POP-related discomfort increasing with heavy load carrying. Our two populations are small and non-representative subsamples of a wide array of circumstances involving women in heavy physical labor in LMICs. In conducting this small comparative study, we are contributing to the scant epidemiologic research examining associations between heavy load carrying activities and reproductive health, and, at the same time, drawing attention to the cumulating evidence that heavy load carrying activities are likely important causal factors for the high prevalence of reproductive morbidity among women in developing countries.

The positive associations between increasing load-carrying exposures and POP-related reproductive discomfort we identified corroborate qualitative reports from women in Nepal of heavy load carrying as a perceived cause of POP [5,7,18,29], and evidence from Ethiopia and Tanzania for significant associations between frequent and sustained load carrying exposures and prevalence of examination-confirmed anatomical POP [20,30]. Despite the positive trends identified between load carrying and adverse reproductive health in our study, the effect estimates had wide, imprecise confidence intervals that included the null. This may indicate that there is no association between heavy load carrying activities and reproductive health or that the sample sizes were insufficient. A recent community-based case control study in Nepal, for example, did not identify an association 
between load carrying duration (at least 12 hours in the last week) or frequency (almost every day, sometimes, not at all) and uterine prolapse confirmed by pelvic examination [21]. Load carrying exposures in our analysis incorporated load weight and frequency of load carrying (number of loads carried per week), which may be important determinants of a woman's likelihood of prolapse. Additionally, due to our limited sample size we were unable to explore the potential impact of other risk factors for POP identified by others, such as sitting/bending positions during work, farming, and, in Nepal, the use of a patuka (cloth band tied around the waist) during load-carrying activities [20,21].

While our study employed questions from scales validated for the clinical evaluation of POP symptoms, the low specificity of each individual symptom for POP may have resulted in the misclassification of symptoms of menstruation or urinary tract infections (UTIs) as being symptoms of POP-related reproductive health discomfort. For example, despite high prevalence of examinationconfirmed POP among women in Ethiopia, the questionnaire used to assess symptoms of prolapse showed very low sensitivity, even among those with obvious and visible POP [30]. Indeed, our reliance on self-report may have resulted in under-reporting of discomfort symptoms, because of social desirability bias, especially when considered in the context of the stigma associated with POP in the largely patriarchal societies from which our two study populations were sampled. Feelings of shame and fear of discrimination and violence have been shown or suspected to impede women's willingness to seek care or report symptoms of POP in a number of countries, including Nepal $[5,6]$, Ethiopia [30,31], Tanzania [20], and Gambia [32], and may also have impacted women's willingness to report symptoms in our study. If under-reporting of reproductive discomfort occurred nondifferentially among groups defined by load-carrying exposures, the association between load carrying and reproductive discomfort is likely to be underestimated. Measurement of reproductive health discomfort in the present study was also limited to current symptoms of POP, with no assessment of previous diagnoses or treatment of POP. Inclusion of women who previously received treatment for POP in our study would likely have biased our estimates towards the null. Future research examining the potential impacts of heavy load carrying on reproductive health should preferably utilize longitudinal designs and also incorporate physical examinations to increase the specificity of outcome diagnosis.

Our limited sample sizes and cross-sectional designs precluded our ability to examine the likely complex ways in which other important predictors of POP and reproductive discomfort, such as early childbearing, inadequate birthing practices, and the length of time which women are allowed to rest from load carrying activities after delivery, may interact with heavy load carrying exposures to impact reproductive health. For example, in rural Tanzania, where the average fertility rate is 6 children per woman, only $55 \%$ of live births were assisted by a skilled attendant [33]. In Nepal, in 2011 , only $36 \%$ of live births were assisted by a skilled attendant and women were often expected to resume carrying loads of wood, water or agricultural crops within a few days of giving birth [6,34]. To that end, a systematic review of detrimental impacts of load carrying in sub-Saharan Africa recommended a minimum resting recovery time following childbirth until participating in physically demanding activities [14]. It is possible that the potential negative health impacts of heavy load carrying may be heightened in women who have recently given birth. Future research should therefore not only be longitudinal, but have larger sample sizes and should also consider the ways in which temporal relationships between load carrying, age, and pregnancy may impact associations with reproductive health. Finally, differing cultural contexts can affect perception and reporting of 
pain and discomfort, thus posing additional challenges in interpreting the findings from these two populations [35].

\section{Conclusions}

Our findings, while exploratory, underscore the need for further research examining associations between heavy load carrying practices and reproductive health. Even among women who do not carry loads as a source of income, cultural expectations often dictate heavy load carrying activities as pervasive parts of their daily activities. Research examining the underlying risk factors for the 'silent epidemic' of POP has the potential to significantly impact the mental and physical health and well-being of women living and working in LMICs.

Author Contributions: Conceptualization, S.I.M., M.N.B., C.H.A, and N.P.; methodology, A.K., J.L.K., S.I.M., M.N.B., C.H.A., and N.P.; validation, A.K. and J.L.K; formal analysis, A.K. and J.L.K.; investigation, A.K., J.L.K., A.M; resources, T.R.S, S.I.M., M.B, C.H.A.; data curation, A.K. and J.L.K.; writing-original draft preparation, A.K.; writing - review and editing, A.K, J.L.K, P.F.N., T.R.S, S.I.M, M.N.B, C.H.A, N.P.; visualization, A.K. and J.L.K; supervision, S.M., M.N.B, C.H.A.; project administration, A.K., J.L.K, A.M., P.F.N., T.R.S ; funding acquisition, A.K. and J.L.K. All authors have read and agreed to the published version of the manuscript.

Funding: This research was supported by the Center for Global Public Health (CGPH) and the Bixby Center for Population, Health \& Sustainability at the University of California, Berkeley.

Acknowledgments: We would like to thank CGPH and the Bixby Center, as well as our many collaborators involved in the design and implementation of this study, particularly, Bina Gurung, Birendra Kunwar, and Dr. Dhirendra Prasad Bhatt. Most importantly, we would like to thank the women who participated in this study, without whom this research would not have been possible.

Conflicts of Interest: The authors declare no conflict of interest. The funders had no role in the design of the study; in the collection, analyses, or interpretation of data; in the writing of the manuscript, or in the decision to publish the results.

\section{References}

1. Walker GJA, Gunasekera P. Pelvic organ prolapse and incontinence in developing countries: review of prevalence and risk factors. Int Urogynecol J 2011;22:127-35. https://doi.org/10.1007/s00192-010-1215-0.

2. The American College of Obstetricians and Gynecologists. Pelvic Organ Prolapse n.d. https://www.acog.org/en/Patient Resources/Videos/Pelvic Organ Prolapse (accessed May 17, 2020).

3. Study on Selected Reproductive Health Morbidities among Women Attending Reproductive Health Camps in Nepal. UNFPA Nepal 2017. https://nepal.unfpa.org/en/publications/study-selected-reproductive-health-morbidities-amongwomen-attending-reproductive-0 (accessed November 3, 2019).

4. Amnesty International. National Alliance for Pelvic Organ Prolapse Management - Nepal. Joint- submission to the United Nations Committee on Economic, Social and Cultural Rights. 2014.

5. Shrestha B, Onta S, Choulagai B, Poudyal A, Pahari DP, Uprety A, et al. Women's experiences and health careseeking practices in relation to uterine prolapse in a hill district of Nepal. BMC Womens Health 2014;14:20. https://doi.org/10.1186/1472-6874-14-20.

6. Amnesty International. Unnecessary Burden: Gender discrimination and uterine prolapse in Nepal,. 2014.

7. Bonetti TR, Erpelding A, Pathak LR. Listening to "Felt Needs": Investigating Genital Prolapse in Western Nepal. Reproductive Health Matters 2004;12:166-75. https://doi.org/10.1016/S0968-8080(04)23110-X. 
8. National Medical Standard for Reproductive Health, Volume II: Other Reproductive Health Issues. Family Health Division; 2003.

9. Nygaard IE, Shaw JM. PHYSICAL ACTIVITY AND THE PELVIC FLOOR. Am J Obstet Gynecol 2016;214:16471. https://doi.org/10.1016/j.ajog.2015.08.067.

10. Jørgensen S, Hein HO, Gyntelberg F. Heavy lifting at work and risk of genital prolapse and herniated lumbar disc in assistant nurses. Occup Med (Lond) 1994;44:47-9. https://doi.org/10.1093/occmed/44.1.47.

11. Woodman PJ, Swift SE, O’Boyle AL, Valley MT, Bland DR, Kahn MA, et al. Prevalence of severe pelvic organ prolapse in relation to job description and socioeconomic status: a multicenter cross-sectional study. Int Urogynecol J 2006;17:340-5. https://doi.org/10.1007/s00192-005-0009-2.

12. Majumdar A, Saleh S, Hill M, Hill SR. The impact of strenuous physical activity on the development of pelvic organ prolapse. Journal of Obstetrics and Gynaecology 2013;33:115-9. https://doi.org/10.3109/01443615.2012.721408.

13. DeLancey JOL. What's new in the functional anatomy of pelvic organ prolapse?: Current Opinion in Obstetrics and Gynecology 2016;28:420-9. https://doi.org/10.1097/GCO.0000000000000312.

14. Porter G, Hampshire K, Dunn C, Hall R, Levesley M, Burton K, et al. Health impacts of pedestrian head-loading: a review of the evidence with particular reference to women and children in sub-Saharan Africa. Soc Sci Med 2013;88:90-7. https://doi.org/10.1016/j.socscimed.2013.04.010.

15. Porter G, Blaufuss K, Acheampong FO. Youth, mobility and rural livelihoods in Sub-Saharan Africa: Perspectives from Ghana and Nigeria. Afr Ins 2008;37:420-31. https://doi.org/10.4314/ai.v37i3.22500.

16. Illegal sand mining rife in Panchthar - The Himalayan Times n.d. https://thehimalayantimes.com/nepal/illegal-sandmining-rife-in-panchthar/ (accessed November 3, 2019).

17. Bodner-Adler B, Shrivastava C, Bodner K. Risk factors for uterine prolapse in Nepal. Int Urogynecol J 2007;18:13436. https://doi.org/10.1007/s00192-007-0331-y.

18. Ravindran S. WOMEN'S EXPERIENCES OF UTERO-VAGINAL PROLAPSE: A QUALITATIVE STUDY FROM TAMIL NADU, INDIA 2007.

19. Asresie A, Admassu E, Setegn T. Determinants of pelvic organ prolapse among gynecologic patients in Bahir Dar, North West Ethiopia: a case-control study. Int J Womens Health 2016;8:713-9. https://doi.org/10.2147/IJWH.S122459.

20. Masenga GG, Shayo BC, Rasch V. Prevalence and risk factors for pelvic organ prolapse in Kilimanjaro, Tanzania: A population based study in Tanzanian rural community. PLOS ONE 2018;13:e0195910. https://doi.org/10.1371/journal.pone.0195910.

21. Devkota HR, Sijali TR, Harris C, Ghimire DJ, Prata N, Bates MN. Bio-mechanical risk factors for uterine prolapse among women living in the hills of west Nepal: A case-control study. Womens Health (Lond Engl) 2020;16:1745506519895175. https://doi.org/10.1177/1745506519895175.

22. Economic and Social Research Foundation, United Nations Development Programme, Government of the United Republic of Tanzania. Tanzania Human Development Report 2014. Economic Transformation for Human Development. 2015.

23. Kadota JL, McCoy SI, Bates MN, Mnyippembe A, Njau PF, Prata N, et al. The Impact of Heavy Load Carrying on Musculoskeletal Pain and Disability Among Women in Shinyanga Region, Tanzania. Annals of Global Health 2020;86:17. https://doi.org/10.5334/aogh.2470.

24. Koyuncu A. Heavy load carrying and musculoskeletal health: An exploratory study of sand miners in Pokhara, Kaski District, Nepal 2020. 
25. Jolliffe IT, Cadima J. Principal component analysis: a review and recent developments. Philosophical Transactions of the Royal Society A: Mathematical, Physical and Engineering Sciences 2016;374:20150202. https://doi.org/10.1098/rsta.2015.0202.

26. Mattsson NK, Nieminen K, Heikkinen A-M, Jalkanen J, Koivurova S, Eloranta M-L, et al. Validation of the short forms of the Pelvic Floor Distress Inventory (PFDI-20), Pelvic Floor Impact Questionnaire (PFIQ-7), and Pelvic Organ Prolapse/Urinary Incontinence Sexual Questionnaire (PISQ-12) in Finnish. Health Qual Life Outcomes 2017;15:88. https://doi.org/10.1186/s12955-017-0648-2.

27. Barber MD, Kuchibhatla MN, Pieper CF, Bump RC. Psychometric evaluation of 2 comprehensive condition-specific quality of life instruments for women with pelvic floor disorders. Am J Obstet Gynecol 2001;185:1388-95. https://doi.org/10.1067/mob.2001.118659.

28. Rogers RG, Kammerer-Doak D, Villarreal A, Coates K, Qualls C. A new instrument to measure sexual function in women with urinary incontinence or pelvic organ prolapse. Am J Obstet Gynecol 2001;184:552-8. https://doi.org/10.1067/mob.2001.111100.

29. Earth B, Sthapit S. Uterine Prolapse in Rural Nepal: Gender and Human Rights Implications. A Mandate for Development. Culture, Health \& Sexuality 2002;4:281-96.

30. Megabiaw B, Adefris M, Rortveit G, Degu G, Muleta M, Blystad A, et al. Pelvic floor disorders among women in Dabat district, northwest Ethiopia: a pilot study. Int Urogynecol J 2013;24:1135-43. https://doi.org/10.1007/s00192-0121981-y.

31. Gjerde JL, Rortveit G, Muleta M, Blystad A. Silently waiting to heal. Int Urogynecol J 2013;24:953-8. https://doi.org/10.1007/s00192-012-1951-4.

32. Scherf C, Morison L, Fiander A, Ekpo G, Walraven G. Epidemiology of pelvic organ prolapse in rural Gambia, West Africa. BJOG: An International Journal of Obstetrics \& Gynaecology 2002;109:431-6. https://doi.org/10.1111/j.14710528.2002.01109.x.

33. Ministry of Health, Community Development, Gender, Elderly and Children (MoHCDGEC). 2015-16 TDHS-MIS Key Findings. Rockville, Maryland, USA: Tanzania Mainland, Ministry of Health (MoH) [Zanzibar], National Bureau of Statistics (NBS), Office of the Chief Government Statistician (OCGS) and ICF.; 2016.

34. Nepal Demographic and Health Survey 2011. n.d.

35. Hondras M, Hartvigsen J, Myburgh C, Johannessen H. Everyday burden of musculoskeletal conditions among villagers in rural Botswana: A focused ethnography. J Rehabil Med 2016;48:449-55. https://doi.org/10.2340/165019772083. 